\title{
Report of a Case: An Intradural between Roots Capillary Hemangioma of Cauda Equina
}

\author{
Abdolkarim Rahmanian ${ }^{1}$, Mohammad Hossein Ashraf ${ }^{2}{ }^{*}$, Seyed Mohammad Owji ${ }^{3}$ \\ ${ }^{1} \mathrm{MD}$, Associate Professor of Neurosurgery, Department of Neurosurgery, Shiraz University of Medical Sciences, Shiraz, Iran \\ ${ }^{2}$ MD, Resident of Neurosurgery, Department of Neurosurgery, Shiraz University of Medical Sciences, Shiraz, Iran \\ ${ }^{3}$ MD, Associate Professor of Pathology, Department of Pathology,Shiraz University of Medical Sciences, Shiraz, Iran
}

* Corresponding Author: Department of Neurosurgery, Shiraz University of Medical Sciences, Zand Avenue, Shiraz, Iran. Tel: +987136274259, Fax:+987136274259, E-mail:ashrafmh@sums.ac.ir

Article Type: Case Report

Received: April 18, 2014, Last revised: July 6, 2015, Accepted: September 22, 2015

\section{Abstract}

Background \& Importance: Cavernous angiomas are typically superficial lesionscreated by anomalous vessels and found in the skin or mucosa, but intradural locations are rare especially in the spine. We report a case of the spinal intradural Cavernous angiomas of the lumbar spine.

Case Presentation: A 53-year-old man presented with a 6-month history of low back pain and bilateral radicular pain. In examinations, the patient was shown to have numbness in the anterior aspect of the right thigh in L2 territoryand a decrease in lower limb tendon reflexes. Magnetic resonance imaging (MRI) revealed at L1-L2 level, a well-defined intradural lesion in conusmedularis measuring about $18 * 12 \mathrm{~mm}$ that shows high signal intensity in T1 images and low signal intensity in T2 images, which causes compression on the cauda roots. Laminectomy of L1-2 was performedfor tumor removal and intradural exploration revealed a small oval shape, brownish cystic like mass surrounded by adherent nerve roots. Complete removal of this tumor was accomplished. Histologic diagnosis wascapillary hemangioma. After operation, the patient's symptoms were improved.

Conclusion: We experienced and reported a rare spinal intradural vascular tumor of the lumbar spine. Histologicdiagnosis was Cavernous angiomas.

Keywords: Intradural; Root; Capillary Hemangioma; Cauda Equina

Please cite this paper as: Rahmanian A, Ashraf M.H, Owji S.M. Report of a Case: An Intradural between Roots Capillary Hemangioma of Cauda Equina. Iran. J. Neurosurg 2015;1(2):44-46.

\section{Introduction}

Cavernous angiomas or cavernomas, which are well-demarcated vascular malformations created by anomalous vessels that are mass of dilated and packed blood vessels with no nervous tissue within the lesion (1). They can occur throughout the central nervous system (CNS) and regarding the literature, those which localized in the spine are extremely rare (2). It has been reported to have an incidence of $5-12 \%$ (3) and accounts for $5 \%$ to $16 \%$ of all vascular lesions of the spine (4). Most of the cases are developed from the vertebral body, and they invade the extradural tissue (2). Today they are being discovered more frequently because of the increased use of MRI. According to our search in Pubmed articles, however there are few cases of cavernoma in cauda equine, but cavernous angioma of rootlets are rare; so we report case of a spinal intradural capillary hemangioma of rootlet in the cauda equina.

\section{Case Presentation}

The 53-year-old man, a worker, presented with pain spreading through the whole spine down to radiating into the legs bilaterally, left greater than right. This symptom lasted about 6 months. His complaint was associated with numbness in the anterior aspect of the right thigh in L2 territory. The objective examination indicated a positive straight leg raising test on the left at 50 degrees, a decrease in lower limb tendon reflexes, with normal muscular tone. No motor weakness was identified. Sensory examination revealed hypoesthesia below the left L2 dermatome and loss of pin prick sensation over the anterior aspect of the left thigh with normal sphincter function. An abnormal gait was present due to burning paresthesia in both legs. On MRI of the spine (Figure 1) at L1-L2 level, a well-defined intradural lesion was found in conus medularis measuring about $18^{*} 12 \mathrm{~mm}$ that shows high signal intensity in $\mathrm{T} 1$ images and low signal intensity in T2 images. This lesion 


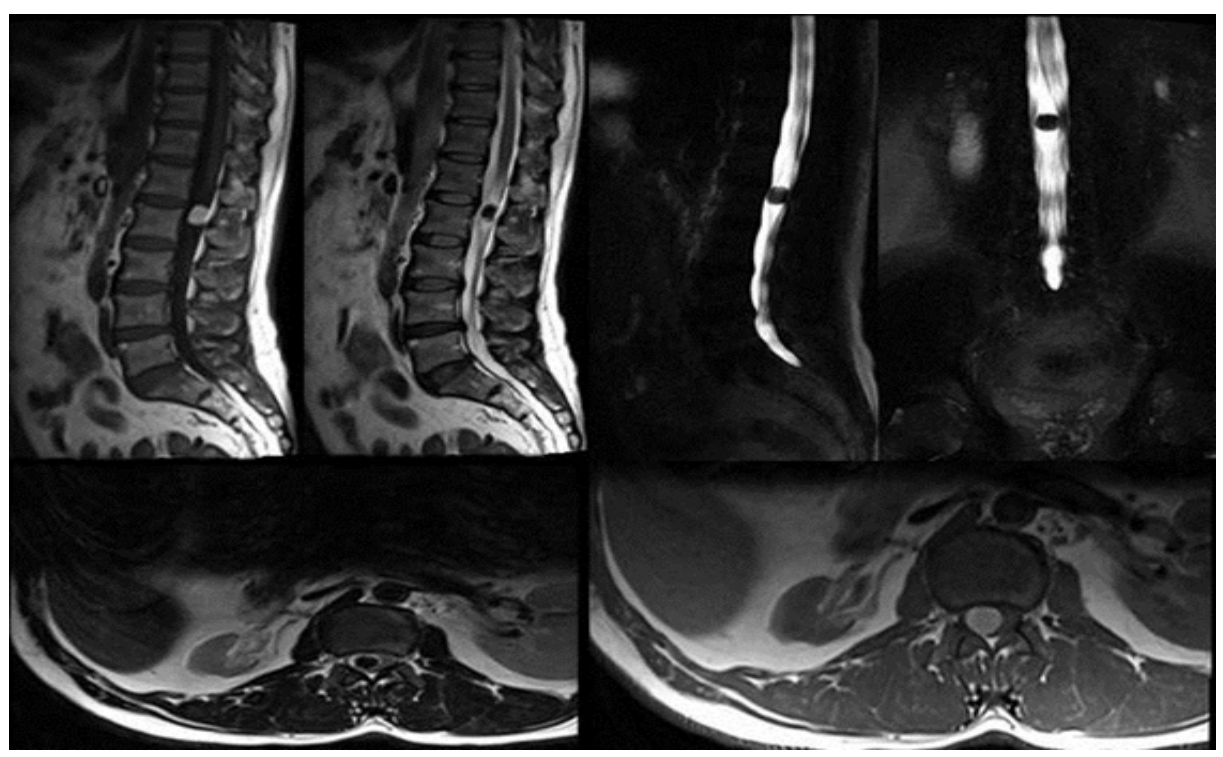

Figure 1. Sagital, Axial and Myelogram MRI of Lumbosacral Area of the Patient in T1 \& T2 Modalities

compressing the cauda roots. After laminectomy at L1 to L2, the dura and the arachnoid were opened and intradural exploration revealed a small $1-\mathrm{cm}$ diameter and oval shape, brownish cystic like mass surrounded by adherent nerve roots. Complete removal of this tumor was accomplished by microdissection of the surrounding arachnoidal adhesions and sharp dissection of the nerve roots adherent to the capsule. After operation, the patient's pain was improved. The post-operative course was normal, and the patient was discharged after 3 days. At three months' follow-up the patient remained pain-free with normal bowel and bladder function. He demonstrated no motor deficit. The specimen consisted of a soft tissue brownish cystic lesion measuring $15^{*} 11 \mathrm{~mm}$. Cut sections show multiple cystic spaces filled with blood clots. Histology showed a highly vascular soft tissue mass, covered by delicate capsule and composed of multiple large vascular channels with different size which were lined by endothelial cells and filled with many RBC's (Figure 2). These findings were consistent with a capillary hemangioma.

\section{Discussion}

Cavernous are generally classified as hamartomas and composed of abnormal, dilated and packed vascular sinusoidal channels without interposed neural tissue (5). The most common location of these vascular malformations is the supratentorial cerebral parenchyma. Cauda equina is an uncommon site, especially nerve rootlets are very rare location $(1,6-8)$. Most of the spinal variants are developed from the vertebral body, and they invade the extradural tissue. But only in rare cases they can be developed with no involvement of vertebral body (2). Pagni et al. (1990) reviewed all intradural cavernous angioma of the spine described in the literature. They concluded that subdural extramedullary cavernous angiomas are the rarest of the cavernomas with only 10 cases documented between 1903 and 1990. Although these vascular malformations are being discovered most frequently because of the widespread use of MRI, they remain still uncommon lesions (9). Khalatbari et al. (2011) reported a rare pediatric intramedullary lesion located within the conus medullaris as a cavernous malformation (10).

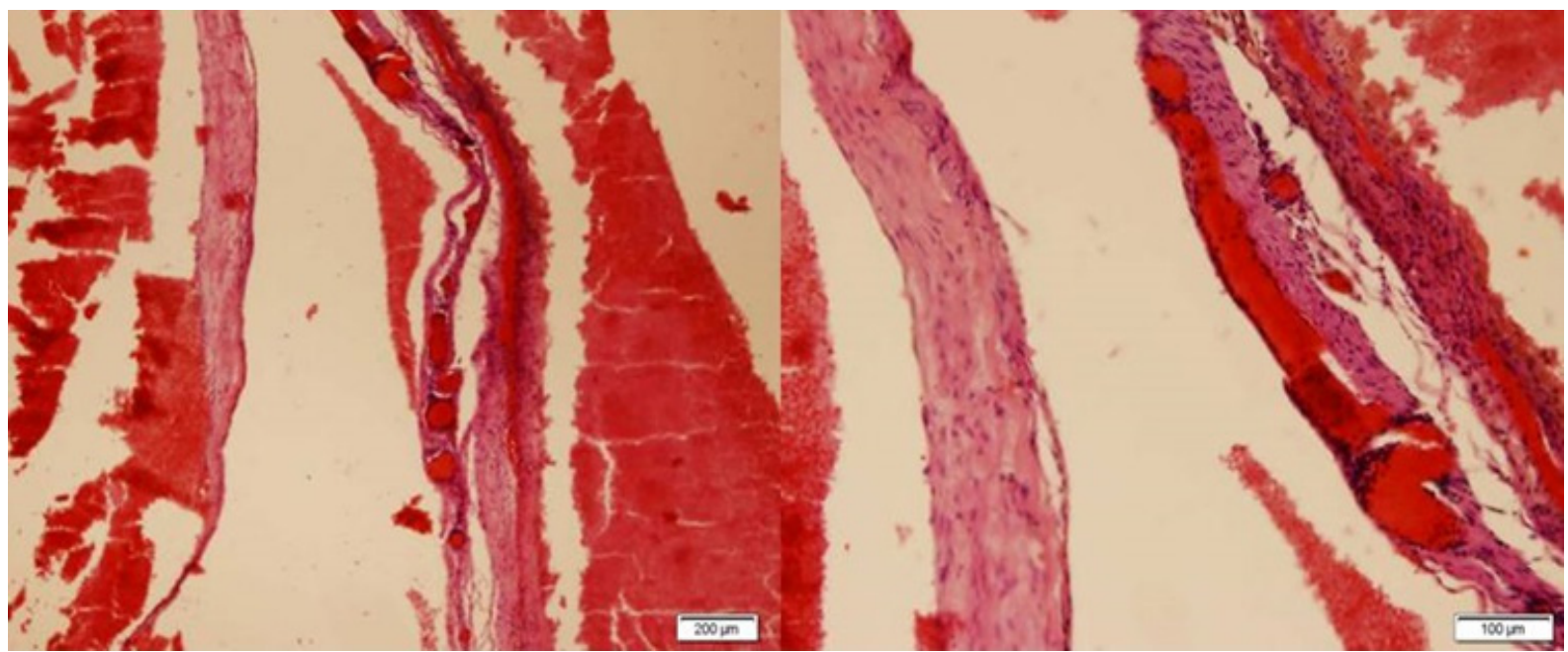

Figure 2. Section of the Lumbar Soft Tissue Mass showing Dilated Large Vascular Channels Lined by Endothelial Cells (H\&E, A: $\times 40$, B: $\times 100)$ 
This possible compression of one or more spinal roots, can obviously mimic symptomatologies typical of ruptured disc or cauda equina tumor. In the differential diagnosis of cauda equine lesions, tumors, vascular, infections and large herniated disc fragments, must be taken into account (11). According to Miyake' report, 14 cases were developed in cauda equina. Most of these cases have been reported to occur between L1 and L3 level (12). As clinical aspect when the cavernous angioma reaches a 'critical volume, it compresses the cauda equina roots leading to a clinical behavior typical of any mass at the same level. Low-back pain and radiculopathy are the main symptoms associated or not with motor deficit or neurologic symptoms secondary to spinal cord compression (13). Sphincter dysfunction and gait abnormalities, generally with a subacute-chronic course might be the other presentation of these lesions according to involved level (1). Although the natural history of spinal cavernomas has not yet been well described, but clearly bleeding and subarachnoid hemorrhage may cause emergent complications such as hydrocephalous or repeated small bleedings, fibrosis, and calcification which cause to chronic symptoms due to increase of the lesion itself (1). From a radiologic point of view, cavernous angiomas are lesions angiographycally occult, often being misdiagnosed as thrombosed arteriovenous malformations, but are easily diagnosed by MRI. Cavernomas may shows a variety of signal intensity on T1- and T2-weighted imaging, depending on the presence of hemosiderin, calcification, and the intensity of blood flow (14). Histologically, cavernous angioma must be distinguished from capillary hemangioma. Capillary hemangioma consists of a myriad of small vessels of capillary size. Cavernous angioma consists of large, dilated hyaline vascular channels arranged in diffuse patterns. They often show thrombosis, perivascular hemosiderin deposition, and calcifications (6). It is presumed that the nerve root capillary is the site of origin of this lesion, and that the adherence of the other roots was a reflection of its associated arachnoiditis. The treatment of choice is complete microsurgical removal. Surgery provides neurological improvement in symptomatic cases and also definitive diagnosis of the lesion. The most frequent surgical finding is that the lesion adheres to the nerve roots, dura matter, or spinal cord extending extraphytically (7). In the present case, cavernous angioma was within one spinal root $(8,9,12)$. Finally, according to published reports and literature these lesions have benign nature and good neurological outcome.

\section{Acknowledgment}

Authors would like to acknowledge all staff of operating room of Namazi Hospital, Shiraz, Iran; and also staff of pathology department for their contribution. This event has also been grateful to the vice chancellor for research and technology affairs, SUMS.

\section{Funding}

None.

\section{Conflicts of Interest}

The authors declare that they have no conflicts of interest.

\section{References}

1. Ramos F Jr, De Toffol B, Aesch B, Jan M. Hydrocephalus and cavernoma of the cauda equina. Neurosurgery 1990;27(1):139-42.

2. Chun SW, Kim SJ, Lee TH, Koo HS. Intra-root cavernous angioma of the cauda equina: a case report and review of the literature. J Korean Neurosurg Soc. 2010; 47(4):291-4. doi: 10.3340/jkns.2010.47.4.291.

3. Hatiboglu MA, Iplikcioglu AC, Ozcan D. Epidural spinal cavernous hemangioma. Neurol Med Chir (Tokyo). 2006; 46(9):455-8.

4. Newton TM, Potts DG. Vascular malformation. San Anselmo,CA: Clavadel Press;1983. 398 p.

5. Duke BJ, Levy AS, Lillehei KO. Cavernous angiomas of the cauda equina: case report and review of the literature. Surg Neurol. 1998;50(5):442-5.

6. Nowak DA, Gumprecht H, Stolzle A, Lumenta CB. Intraneural growth of a capillary haemangioma of the cauda equina. Acta Neurochir (Wien). 2000; 142(4): 463-7.

7. Nozaki $\mathrm{K}$, Inomoto $\mathrm{T}$, Taagi $\mathrm{Y}$, Hashimoto $\mathrm{N}$. Spinal intradural extramedullary cavernous angioma. Case report. J Neurosurg. 2003; 99: 316-9. 8. Falavigna A, Righesso Neto O, dos Santos JA, Ferraz FA. Cavernous angioma of the cauda equina: case report. Arq Neuropsiquiatr. 2004; 62: 531-4. 9. Pagni CA, Canavero S, Forni M. Report of a cavernoma of the cauda equina and review of the literature. Surg Neurol 1990; 33(2): 124-31.

10- Khalatbari MR, Hamidi M, Moharamzad Y. Pediatric intramedullary cavernous malformation of the conous medullaris: case report and review of the literature. Childs Nerv Syst. (2011) 27:507-511.

11. Shin JH, Lee HK, Jeon SR, Park SH. Spinal intradural capillary hemangioma: MR findings. AJNR Am J Neuroradiol. 2000;21(5):954-6.

12. Caroli E, Acqui M, Trasimeni G, Di Stefano D, Ferrante L. A case of intraroot cauda equina cavernous angioma: clinical considerations. Spinal Cord. 2007; 45(4):318-21.

13. Cecchi PC, Rizzo P, Faccioli F, Bontempini L, Schwarz A, Bricolo A. Intraneural cavernous malformation of the cauda equine. J Clin Neurosci. 2007;14(10):984-6.

14. Santoro A, Piccirilli M, Frati A, Salvati M, Innocenzi G, Ricci G, Cantore $\mathrm{G}$. Intramedullary spinal cord cavernous malformations: report of ten new cases. Neurosurg Rev. 2004;27(2): 93-8.

\section{Comments}

Rahmanian and colleagues have reported 18th case of capillary hemangioma of cauda equina and 51st in the spine based on the latest reported cases $(1,2)$. A 53 years old man both shows common age and sex of this rare tumor of the spine. Clinically, capillary hemangioma can be asymptomatic or presents with pain and lowly progressive sensory loss. Clinically, it is difficult to be differentiated from discopathy. Capillary hemangioma is isointense in T1 MRI and mildly hyperintense in T2 and intensely enhancing after gadolinium injection. The homogenous enhancement is also seen in other types of more common benign tumors such as schwannoma and meningioma. Capillary hemangioma is an intradural benign, encapsulated tumor which does not invade. Microscopically, capillary hemangioma consists of countless small vessels in the size of capillaries which has a single layer of endothelium. However, cavernous hemangioma consists of dilated sinusoidal vessels with thrombosis and hemosiderin. Enbloc tumor resection is the procedure of choice for the tumor. Operation under microscope is recommended.

Vafa Rahimi-Movaghar, MD, Professor of Neurosurgery, Sina Trauma and Surgery Research Center, Tehran University of Medical Sciences, Tehran, Iran

\section{References}

1. Pignotti F, Coli A, Fernandez E, Montano N. Capillary hemangioma of the cauda equina.Surg Neurol Int. 2015 Aug 10;6:133.

2. Liu JJ, Lee DJ, Jin LW, Kim KD. Intradural extramedullary capillary hemangioma of the cauda equina: Case report and literature review. Surg Neurol Int. 2015 Apr 22;6 (Suppl 3):S127-31. 